\title{
Does Combined Intra- and Extraarticular ACL Reconstruction Improve Function and Stability? A Meta-analysis
}

\author{
Fernando Cury Rezende MD, Vinicius Ynoe de Moraes MD, Ana Luiza Cabrera Martimbianco Bsc, \\ Marcus Vinícius Luzo PhD, Carlos Eduardo da Silveira Franciozi PhD, \\ João Carlos Belloti PhD
}

Received: 24 October 2014/Accepted: 25 March 2015/Published online: 7 April 2015

(C) The Association of Bone and Joint Surgeons (B) 2015

\begin{abstract}
Background ACL reconstruction aims to restore knee function and stability; however, rotational stability may not be completely restored by use of standard intraarticular reconstruction alone. Although individual studies have not shown the superiority of combined ACL reconstruction compared with isolated intraarticular reconstruction in terms of function and stability, biomechanical principles suggest a combined approach may be helpful, therefore pooling (meta-analyzing) the available randomized clinical studies may be enlightening.

Questions/purposes We performed a meta-analysis to determine whether combining extraarticular with intraarticular ACL reconstruction would lead to: (1) similar knee function measured by the IKDC evaluation, return-to-
\end{abstract}

Each author certifies that he or she has no commercial associations (eg, consultancies, stock ownership, equity interest, patent/licensing arrangements, etc) that might pose a conflict of interest in connection with the submitted article.

All ICMJE Conflict of Interest Forms for authors and Clinical Orthopaedics and Related Research ${ }^{\circledR}$ editors and board members are on file with the publication and can be viewed on request.

Each author certifies that his or her institution approved the human protocol for this investigation, that all investigations were conducted in conformity with ethical principles of research, and that informed consent for participation in the study was obtained.

Electronic supplementary material The online version of this article (doi:10.1007/s11999-015-4285-y) contains supplementary material, which is available to authorized users.

F. C. Rezende ( $)$, V. Y. de Moraes, A. L. C. Martimbianco, M. V. Luzo, C. E. da Silveira Franciozi, J. C. Belloti Department of Orthopedics and Traumatology, Federal University of São Paulo, Borges Lagoa Street 783, Sao Paulo, SP 04038-032, Brazil

e-mail: rezendefernando@hotmail.com activity, and Tegner Lysholm scores, compared with isolated intraarticular reconstruction; (2) increased stability measured by pivot shift and instrumented Lachman examination; and (3) any differences in complications and adverse events?

Methods To identify randomized controlled trials (RCTs) comparing combined intra- and extrarticular ACL reconstruction (combined reconstruction) with intraarticular ACL reconstruction only, we searched MEDLINE, EMBASE, SPORTDiscus, Latin American and Caribbean Health Sciences (LILACS), and the Cochrane Central Register of Controlled Trials, and followed the Preferred Reporting Items for Systematic Reviews and Meta-Analyses (PRISMA) criteria. The main outcomes we sought were patient function and stability and complications after ACL reconstruction. Of 386 identified studies, eight RCTs were included $(\mathrm{n}=682$ participants; followup, 12-84 months; men to women ratio, 2.17:1) in our meta-analysis. Study quality (internal validity) was assessed using the Cochrane risk-of-bias tool; in general, we found a moderate quality of evidence of the included studies.

Results When functional outcomes were compared, we found no difference between patients who underwent intraarticular ACL reconstruction only and those who underwent combined reconstruction (IKDC, return-to-activity, and Tegner Lysholm scores). However, patients who underwent combined reconstruction were more likely to show improved stability based on the pivot shift test (risk ratio $[R R], 0.95 ; 95 \% \mathrm{CI}, 0.91-0.99 ; \mathrm{p}=0.02$ ) and Lachman test (RR, 0.93; 95\% CI, 0.88-0.98; $\mathrm{p}=0.01)$. In addition, our meta-analysis found no difference between the two treatments in terms of general complications or adverse events (RR, 1.31; 95\% CI, 0.70-2.34; $\mathrm{p}=0.40$ ) and the proportion of patients whose reconstructions failed (RR, 2.88; 95\% CI, 0.73-11.47; $\mathrm{p}=0.13$ ). 
Conclusion Combined intra- and extraarticular ACL reconstruction provided marginally improved knee stability and comparable failure rates but no difference in patientreported functional outcomes scores. Complications and adverse events such as knee stiffness may be underreported and technical factors such as graft placement were difficult to evaluate. Future studies are needed to determine whether the small differences in additional stability warrant the potential morbidity of the additional extraarticular procedure and to determine long-term failure rates.

\section{Introduction}

ACL reconstruction is reported to produce good or excellent results in more than $90 \%$ of patients [9]; however, it remains unclear whether intraarticular single-bundle ACL reconstruction can provide adequate restraint against rotational forces in all ACL-deficient knees [21, 34, 37]. Residual rotational instability after ACL reconstruction is thought to be a cause of recurrent injuries [6]. The more anatomic double-bundle ACL reconstruction was proposed to overcome potential rotatory instability of the knee, but consensus has not been reached regarding its widespread use [26, 27, 44]. In addition, studies have shown that the posterolateral bundle contributes little to rotational stability of the knee; this function might be performed by peripheral structures such as the anterolateral ligament [8, 28, 45]. Although not yet well established, these findings may support the concept of anterolateral instability associated with ACL injury described by Hughston [17] but perhaps neglected in the modern era of arthroscopic intraarticular ACL reconstruction.

A better understanding is needed of the relationship between residual rotatory instability after standard intraarticular ACL reconstruction [10, 21, 37] and the potential benefits of adding a lateral extraarticular reconstruction [25]. Because some ACL injuries result in damage to central and peripheral structures leading to complex rotatory instability $[5,22]$, the addition of a lateral extraarticular procedure to intraarticular ACL reconstruction may stabilize rotational knee laxity and decrease graft forces [12, 24].

However, the extraarticular procedure adds to the morbidity of patients undergoing ACL surgery [30]. The combined reconstruction technique is more technically demanding, requires an additional incision, and is more time-consuming [38]. Increased incidence of patellofemoral crepitation and loss of knee motion also are associated with certain extraarticular techniques [3]. Furthermore, studies have not shown the superiority of combined ACL reconstruction compared with intraarticular reconstruction alone $[1,14]$.
We conducted a systematic review and meta-analysis of Level I randomized controlled trials (RCTs) to determine whether adding an extraarticular ACL reconstruction (any technique) led to (1) similar knee function measured by IKDC evaluation, return-to-activity, and Tegner Lysholm scores compared with isolated intraarticular reconstruction; (2) increased stability measured by pivot shift and instrumented Lachman examination; and (3) any difference in complications and adverse events.

\section{Search Strategy and Criteria}

We registered the systematic review protocol at the PROSPERO international database [43]. In addition, we followed the recommendations of the Preferred Reporting Items for Systematic Reviews and Meta-Analyses (PRISMA) statement [20].

RCTs comparing combined intra- and extraarticular ACL reconstruction with intraarticular ACL reconstruction only were eligible for our meta-analysis. Studies were included if they evaluated skeletally mature individuals of both sexes with ACL rupture who had undergone primary reconstruction regardless of graft type or reconstruction technique (intraarticular or extraarticular). Trials in which patients underwent revision surgery after previous ACL reconstruction were excluded.

Two authors (FCR, VYdM) independently searched the electronic databases MEDLINE, EMBASE, SPORTDiscus, Latin American and Caribbean Health Sciences (LILACS), and the Cochrane Central Register of Controlled Trials from inception to April 2014. Ongoing and recently completed trials were identified by searching ClinicalTrials.gov (Appendix 1; supplemental materials are available with the online version of $\left.C O R R^{\circledR}\right)$. We did not apply any restrictions based on languages and translation services were used when needed. Reference lists from relevant articles were checked for completeness. We also hand searched abstracts of conferences (from first meeting available online to 2014) of the International Society of Arthroscopy, Knee Surgery and Orthopaedic Sports Medicine; American Orthopaedic Society for Sports Medicine; and American Academy of Orthopaedic Surgeons.

Our literature search identified a total of 386 studies, and after exclusion of obviously irrelevant and duplicate reports, nine full-text articles were retrieved for evaluation. We have recognized two reports of the same study; although we combined useful data from both reports, most relevant information was extracted from the full text report [14]. We excluded another study [29] that was not an RCT. The remaining eight studies (Appendix 2; supplemental materials are available with the online version of $C O R R^{\circledR}$ ) 


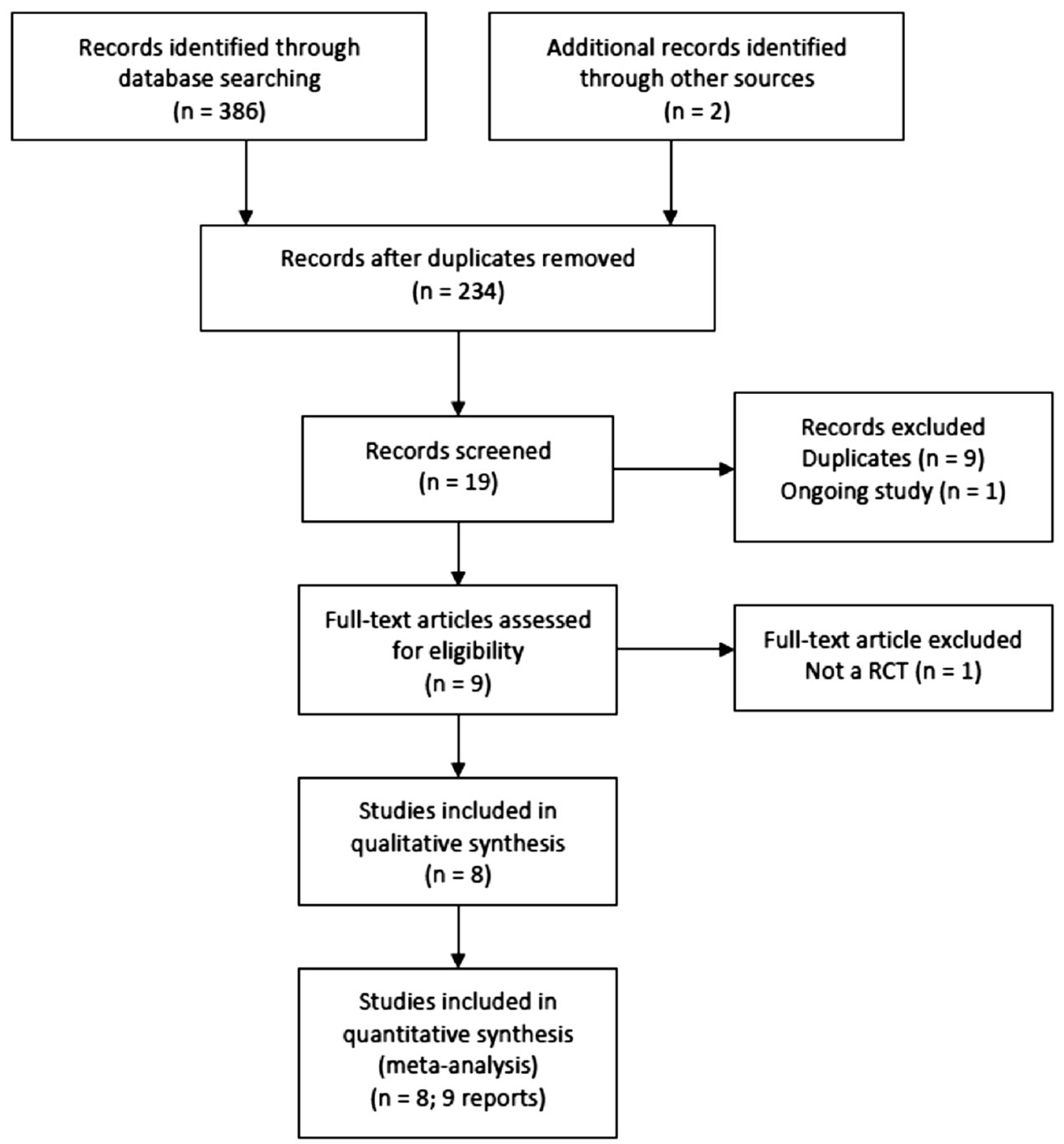

Fig. 1 The study flowchart is shown. RCT $=$ randomized controlled trial; Studies included $(\mathrm{n}=8$; 9 reports $)=$ one study had two reports derived from the same sample.

met the inclusion criteria for our systematic review (Fig. 1).

Two authors (FCR, ALCM) independently extracted data from eligible studies by completing a predesigned data form. Function and stability (primary outcomes) were assessed as: (1) results of validated measures of knee function [18, 23, 40]; (2) return to previous activity level; and (3) knee stability (pivot shift test, Lachman test, and KT-1000 and KT-2000 arthrometer [MEDmetric Corporation, San Diego, CA, USA] testing of side-to-side differences). Complications, adverse events, and graft failures (secondary outcomes) were assessed as treatment failure (graft failure), adverse events (recurrent meniscal injuries, infection, and knee stiffness), and radiographic findings (degenerative changes).

Study quality (internal validity) was assessed using the Cochrane risk-of-bias tool [16]. In general, we found the included studies to be of moderate quality on this scale. As would be expected in a population of surgical RCTs, the most common shortcoming was blinding of patients and surgical personnel (Fig. 2).

All statistical analyses were performed using Review Manager (RevMan 5.1; The Nordic Cochrane Centre, The Cochrane Collaboration, Copenhagen, Denmark) statistical software [41]. Treatment effects were expressed as risk ratios (RRs) for dichotomous outcomes and mean differences for continuous outcomes with 95\% CIs. For data judged to be homogenous, a fixed-effect meta-analysis was performed. The heterogeneity of treatment effects was appraised visually by observing overlapping CIs in forest plots and the direction and magnitude of treatment effects. In addition, $\mathrm{I}^{2}$ statistics were calculated for an objective assessment of heterogeneity. High heterogeneity was indicated by the absence of overlapping CIs in forest plots and $\mathrm{I}^{2}$ greater than $50 \%$ and the reasons for heterogeneity were investigated. Subgroup analysis was performed when 


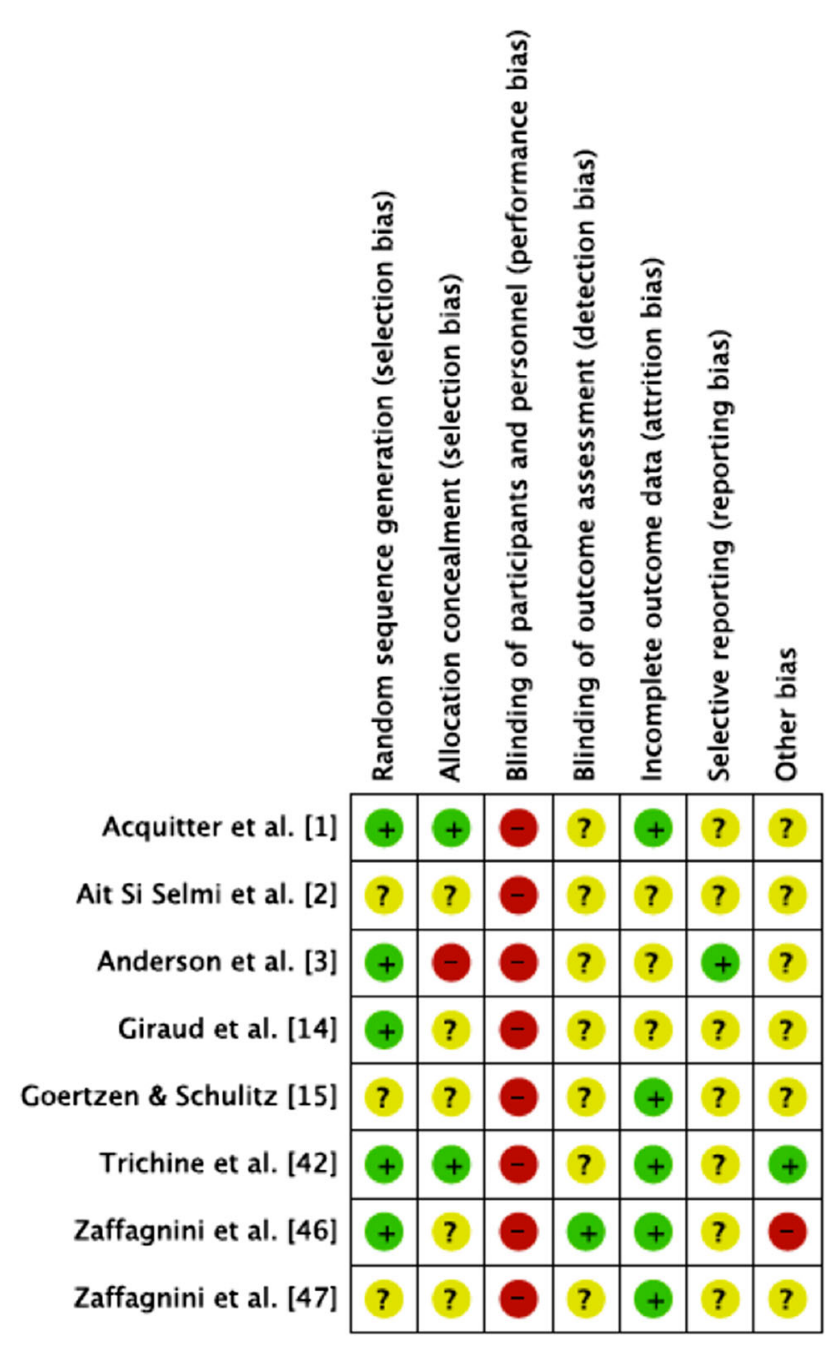

Fig. 2 The methodologic characteristics of the studies included in our meta-analysis are shown. $+=$ low risk of bias; $-=$ high risk of bias.

feasible. Publication bias was assessed by visual inspection of funnel plots from primary outcomes (Fig. 3). Assessments may lack precision owing to the small number of trials. The studies are well distributed along the plot and publication bias is not a major concern. As a safeguard, we hand-searched gray literature in the area aiming to find studies with nonrelevant or negative results.

\section{Results}

Function and Stability

IKDC subjective scores did not differ with the numbers available between patients who underwent intraarticular ACL reconstruction only compared with patients who underwent combined ACL reconstruction (RR, $-0.21 ; 95 \%$ $\mathrm{CI},-4.52$ to $4.09 ; \mathrm{p}=0.94)$. The IKDC objective score is
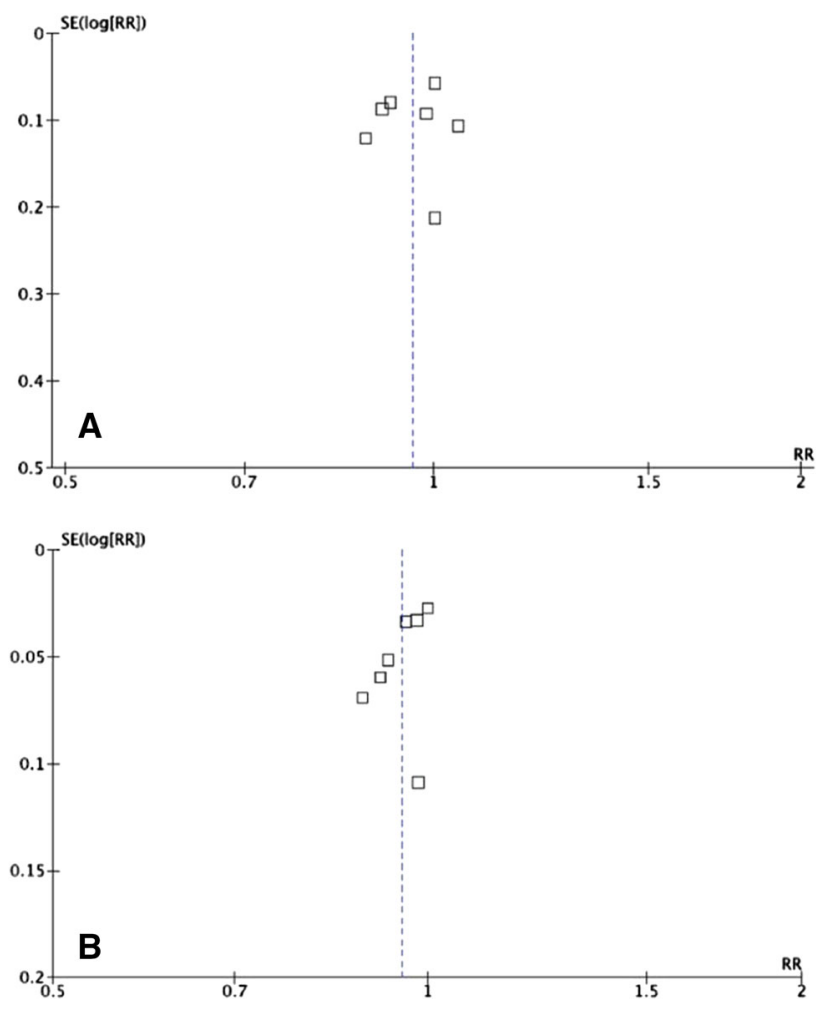

Fig. 3A-B The funnel plots show the standard error (SE) and risk ratio (RR) for the (A) IKDC and (B) pivot shift test scores.

reported as A (normal), B (nearly normal), C (abnormal), or D (severely abnormal) [18]. IKDC scores of A or B did not differ between the two groups (RR, 0.96; 95\% CI, 0.89-1.03; $\mathrm{p}=0.30$ ) (Fig. 4). In addition, treatment groups did not differ regarding Tegner Lysholm activity scores and the proportion of patients able to return to their previous activity levels (Tegner Lysholm scores: mean difference, -0.44 , [95\% CI, -2.30 to 1.42 ], $\mathrm{p}=0.64$; return to previous activity level: RR, $0.01,[95 \% \mathrm{CI},-0.07$ to 0.09 ], $\mathrm{p}=0.73$ ).

The proportion of patients with normal or nearly normal pivot shift and Lachman tests was greater in the group treated with combined ACL reconstruction (pivot shift: $\mathrm{RR}, 0.95$, [95\% CI, 0.91-0.99], $\mathrm{p}=0.02$; Lachman test: RR, 0.93, [95\% CI, 0.88-0.98], $\mathrm{p}=0.01$ ) (Fig. 5). However, the proportion of patients with side-to-side difference greater than $3 \mathrm{~mm}$ per KT-1000 and KT-2000 arthrometer measurements did not differ with the numbers available between groups (RR, 0.90, [95\% CI, 0.73-1.12], $\mathrm{p}=0.35$; RR 1.05, [95\% CI, 0.85-1.29], $\mathrm{p}=0.65$, respectively).

Complications, Adverse Events, and Graft Failures

Overall complications and adverse events did not differ with the numbers available between the two treatment 


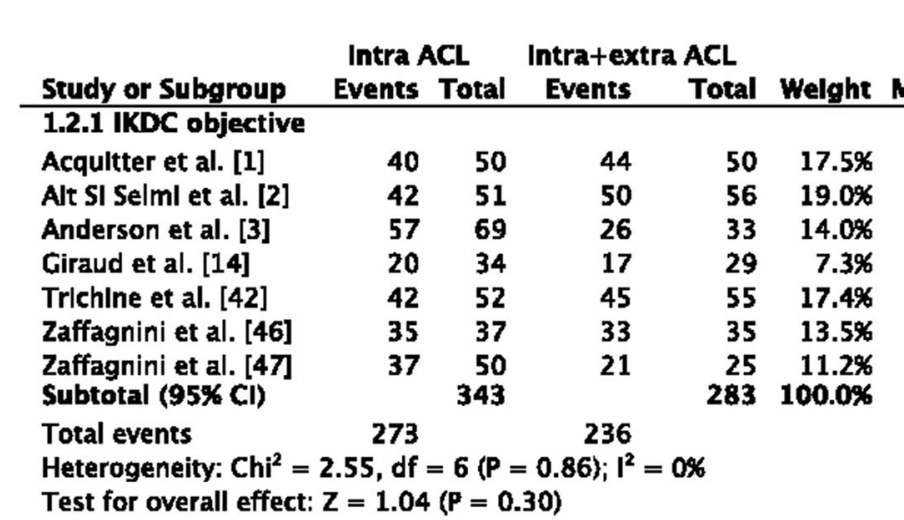

Fig. 4 A comparison of IKDC objective knee evaluation scores is shown. The forest plot shows no significant difference in scores between patients who underwent intraarticular ACL reconstruction
RIsk Ratlo

H, Flxed, 95\% Cl

$0.91[0.77,1.08]$

$0.92[0.79,1.08]$

$1.05[0.85,1.29]$

$1.00[0.66,1.52]$

$0.99[0.82,1.18]$

$1.00[0.90,1.12]$

$0.88[0.69,1.12]$

$0.96[0.89,1.04]$
RIsk Ratlo

$M-H$, Flxed, 95\% CI

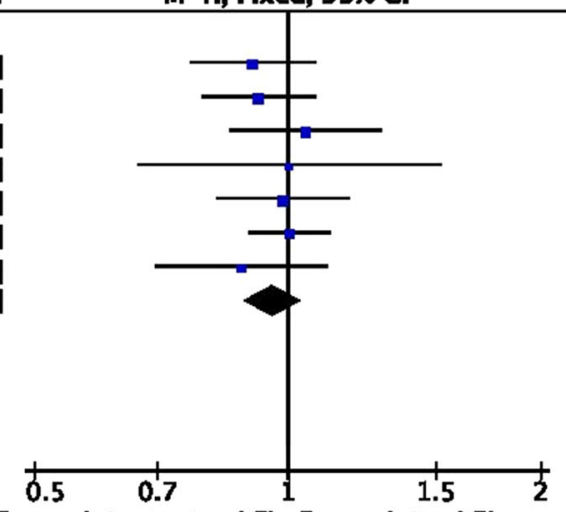

Favors Intra+extra ACL Favors Intra ACL

only and those who underwent combined intra- and extraarticular ACL reconstruction. $\mathrm{M}-\mathrm{H}=$ Mantel-Haenszel; intra = intraarticular; extra $=$ extraarticular.

\begin{tabular}{|c|c|c|c|c|c|c|}
\hline Study or Subgroup & $\begin{array}{l}\text { intra } A \\
\text { Events }\end{array}$ & $\begin{array}{l}\mathrm{CL} \\
\text { Total }\end{array}$ & $\begin{array}{l}\text { intra+extra } \\
\text { Events }\end{array}$ & $\begin{array}{l}\mathrm{ACL} \\
\text { Total }\end{array}$ & Weight & $\begin{array}{c}\text { Risk Ratio } \\
\text { M-H, Fixed, } 95 \% \mathrm{CI}\end{array}$ \\
\hline \multicolumn{7}{|c|}{ 1.6.1 Pivot shift (normal or nearly normal) } \\
\hline Acquitter et al. [1] & 44 & 50 & 48 & 50 & $16.4 \%$ & $0.92[0.82,1.03$ \\
\hline Ait Si Selmi et al. [2] & 49 & 51 & 56 & 56 & $18.4 \%$ & $0.96[0.90,1.03$ \\
\hline Anderson et al. [3] & 53 & 68 & 27 & 34 & $12.3 \%$ & $0.98[0.79,1.21]$ \\
\hline Giraud et al. [14] & 30 & 34 & 29 & 29 & $10.9 \%$ & $0.89[0.77,1.01]$ \\
\hline Trichine et al. [42] & 50 & 52 & 54 & 55 & $17.9 \%$ & $0.98[0.92,1.05]$ \\
\hline Zaffagnini et al. [46] & 35 & 35 & 37 & 37 & $12.5 \%$ & $1.00[0.95,1.05]$ \\
\hline $\begin{array}{l}\text { Zaffagnini et al. [47] } \\
\text { Subtotal }(95 \% \mathrm{Cl})\end{array}$ & 46 & $\begin{array}{r}50 \\
340\end{array}$ & 25 & $\begin{array}{r}25 \\
286\end{array}$ & $\begin{array}{r}11.6 \% \\
100.0 \%\end{array}$ & $\begin{array}{l}0.93[0.84,1.03] \\
0.95[0.91,0.99]\end{array}$ \\
\hline Total events & 307 & & 276 & & & \\
\hline
\end{tabular}

Heterogeneity: $\mathrm{Chi}^{2}=5.75, \mathrm{df}=6(P=0.45) ; \mathrm{I}^{2}=0 \%$

Test for overall effect: $Z=2.29(P=0.02)$

A

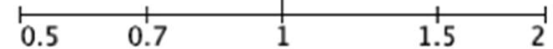

Favors intra+extra $\mathrm{ACL}$ Favors intra $\mathrm{ACL}$

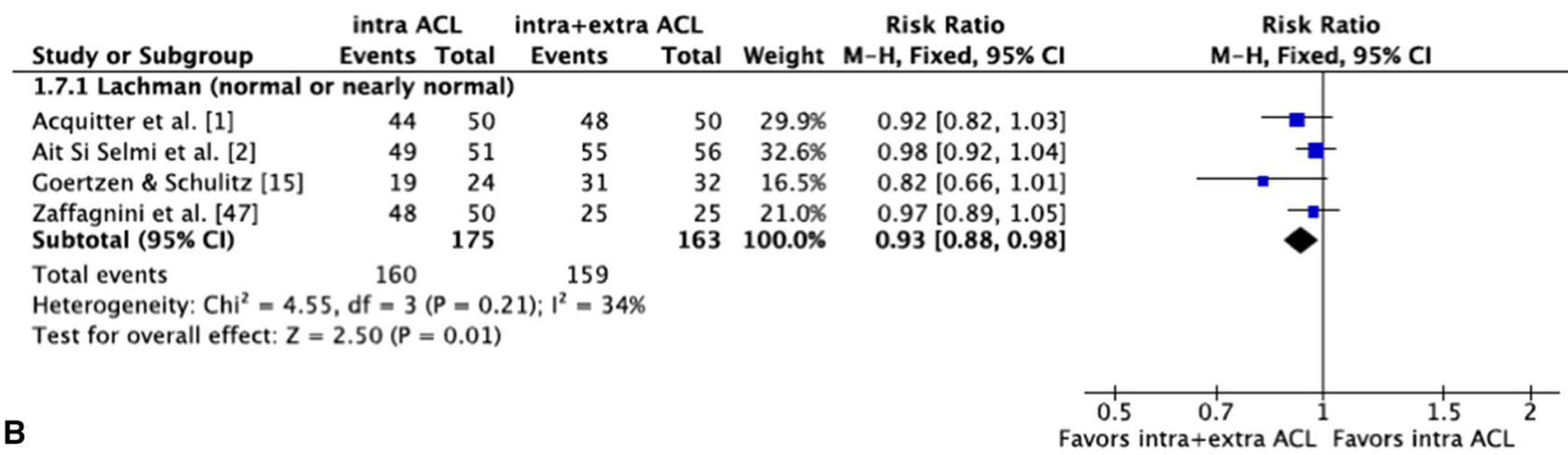

Fig. 5A-B Comparisons of (A) pivot shift and (B) Lachman test results is shown. The forest plots show a significantly higher proportion of normal or nearly normal scores for patients who underwent combined intra- and extraarticular ACL reconstruction

groups (RR, 1.31; 95\% CI, 0.70-2.44; $\mathrm{p}=0.84$ ). Five studies $[1,3,15,42,46]$ reported graft failure after ACL reconstruction; three of the studies had no subjects with compared with those who underwent intraarticular ACL reconstruction only. $\mathrm{M}-\mathrm{H}=$ Mantel-Haenszel; intra $=$ intraarticular; extra $=$ extraarticular.

graft failure $[15,42,46]$, leaving two studies for our metaanalysis $[1,3]$, which indicated no difference between the two treatments in terms of the proportion of patients whose 


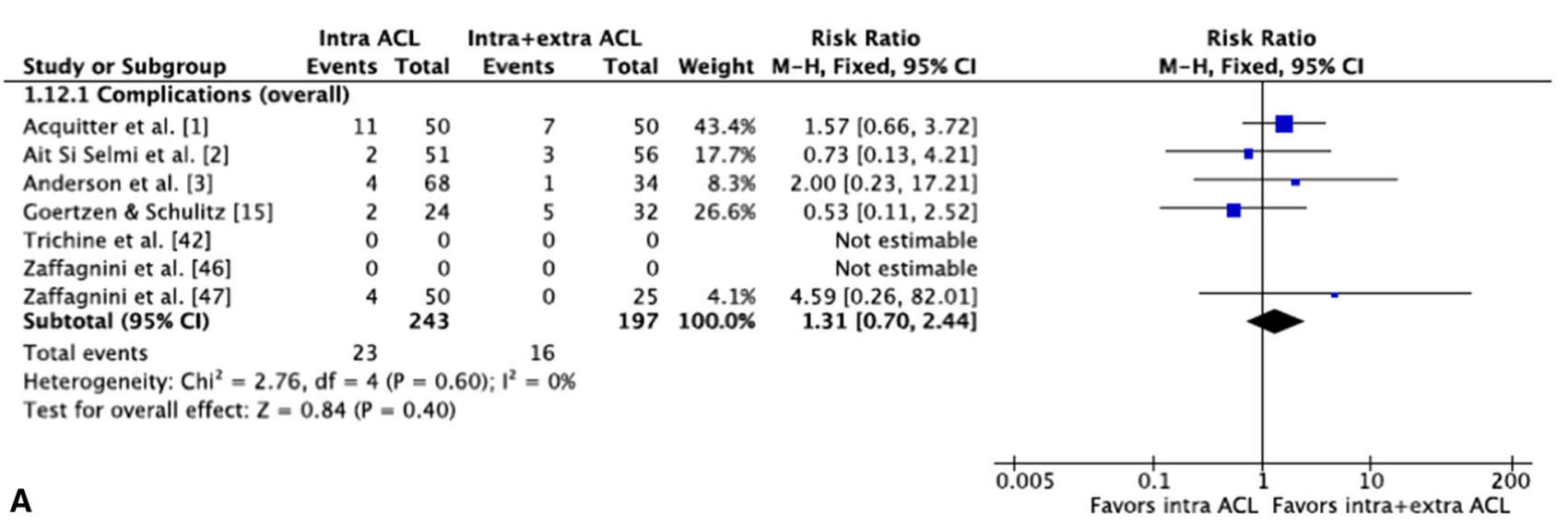

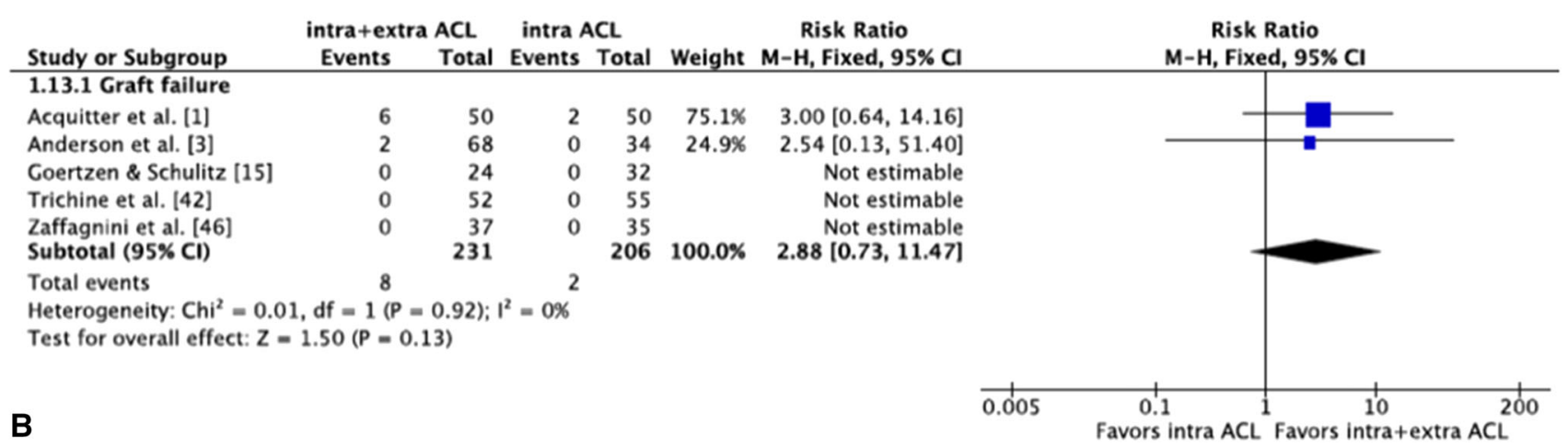

Fig. 6A-B The overall (A) complication and (B) failure rates after ACL reconstruction are shown. The forest plots show that these rates did not differ significantly between patients who underwent intraarticular ACL reconstruction only and those who underwent combined intra- and extraarticular ACL reconstruction. M-H = Mantel-Haenszel; intra $=$ intraarticular; extra $=$ extraarticular. reconstruction failed (RR, 2.88; 95\% CI, 0.73-11.47; $\mathrm{p}=0.13$ ) (Fig. 6). The rates of specific complications (infection, knee stiffness, and recurrent meniscal injury) that were individually meta-analyzed and the proportion of patients with radiographic evidence of degenerative changes were not different between the two groups (RR, $0.99 ; 95 \%$ CI, $0.60-1.64 ; \mathrm{p}=0.98$ ).

\section{Subgroup Analyses}

Analyses were performed to determine whether outcomes after ACL reconstruction varied according to graft type. Pooling the data for studies evaluating ACL reconstruction with bone-patellar tendon-bone (BPTB) grafts only, the proportion of patients with normal or nearly normal results of pivot shift and Lachman tests were not different between the two treatment groups (pivot shift: RR, 0.96, [95\% CI, 0.91-1.00], $\mathrm{p}=0.05$; Lachman: RR, 0.96, [95\% CI, 0.911.01], $\mathrm{p}=0.13$ ). Pooling the data for studies evaluating ACL reconstruction with hamstring grafts only, the proportion of patients with normal or nearly normal Lachman test results and a side-to-side difference less than $3 \mathrm{~mm}$ on
KT-1000 arthrometer testing was greater in the combined reconstruction group (Lachman test: RR, 0.87, [95\% CI, 0.77-0.99], $\mathrm{p}=0.03$; KT-1000: RR, 0.88, [95\% CI, 0.35$1.41], \mathrm{p}=0.001$ ) (Fig.7). However, the two groups did not differ in terms of the proportion of participants with normal or nearly normal pivot shift test results (RR, 0.94; 95\% CI, $0.86-1.04 ; \mathrm{p}=0.21 ; \mathrm{I}^{2}=69 \%$ ).

\section{Discussion}

Relatively consistent results of standard isolated intraarticular ACL reconstruction have been reported and findings have shown recovery of knee function in the majority of patients [9]. However, rotational stability may not be restored by intraarticular reconstruction alone [6, 21, 37]. The main finding of our meta-analysis was that compared with intraarticular ACL reconstruction only, combined intra- and extraarticular ACL reconstruction resulted in no differences in knee function or complications. Although knee stability was superior in the combined intra- and extraarticular ACL reconstruction group, pivot shift and Lachman test results were only marginally improved. 


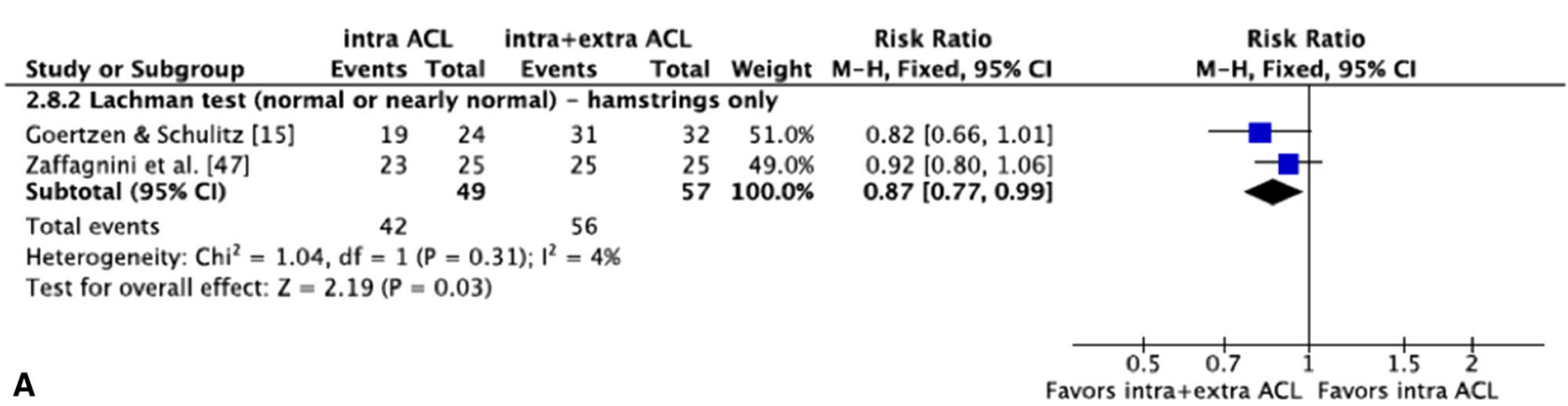

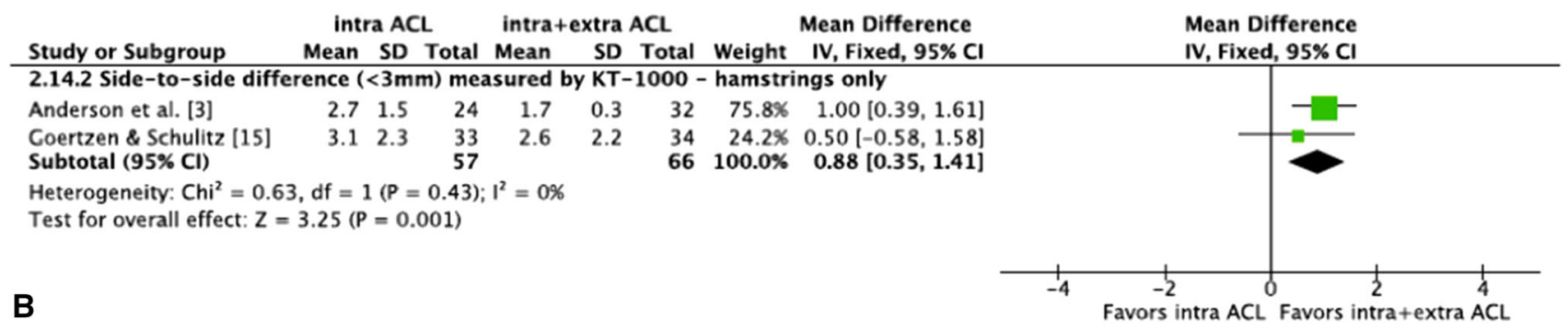

Fig. 7A-B Comparisons of the (A) Lachman test and (B) KT-1000 arthrometer test results after ACL reconstruction with only hamstrings grafts are shown. Theforest plots show a significantly higher proportion of patients with normal or nearly normal Lachman test results and a side-to-side difference less than $3 \mathrm{~mm}$ on KT-1000

Potential weaknesses of our meta-analysis include methodologic limitations such as possibly missing data (from nonpublished studies) and selective reporting. The included studies incurred losses to followup and reasons for patient loss to followup were underreported. The limited number of included trials determined outcomes with a small number of patients pooled for analyses, lessening the power of some comparisons. As literature interest in this topic may increase, future analyses may reveal additional answers to the uncertainties of our review. Considerable variability in ACL reconstruction techniques evaluated in the included studies was another concern. Although it would be reasonable to think that the variability would lead to high heterogeneity, that was not the case. Most outcomes showed low heterogeneity, allowing conclusions to be drawn. Subgroup analyses, which were limited to graft type, revealed differential effects of BPTB and hamstring grafts, as previous reports have suggested [31, 33]. In addition, most extraarticular procedures described in the included trials are nonanatomic. As knowledge of the anterolateral compartment anatomy of the knee evolves, repair techniques of specific structures and more anatomic extraarticular reconstruction techniques may be developed, which may improve results and minimize donor site morbidity [12].

Another relevant issue is evaluation of knee rotatory instability. Improvement in patient satisfaction and knee function has been shown to maintain straight association with arthrometer testing in the combined intra- and extraarticular ACL reconstruction group compared with those who underwent intraarticular ACL reconstruction only. $\mathrm{M}-\mathrm{H}=$ Mantel-Haenszel; intra = intraarticular; extra $=$ extraarticular.

knee rotatory stability, therefore interest has grown in increasing reliability of diagnostic and treatment methods of rotatory stability after ACL reconstruction [19]. The pivot shift test remains the main tool to address rotational instability, as other knee rotation assessments are not standardized [4]. However, confounding factors such as differences in performance methods, strength torque applied, and excessive subjectivity in the examiner's interpretation of pivot shift evaluation may diminish its usefulness [48]. As a result, knee rotation objective outcomes should be interpreted with caution given the low reliability of available tools.

A broadly discussed topic in current ACL research is graft placement [36], which has straight correlation with knee rotational stability although it was not considered in the trials of our review. Furthermore, reports showing residual instability after ACL reconstruction mostly are outdated, and consequently an old-fashioned vertical tunnel might be the origin of this high rate of reported rotational instability $[6,21$, 37]. Therefore, considering the actual trend of more horizontal and anatomic graft placement, which also aims to improve rotational control, we may assume that an additional extraarticular procedure becomes a more invasive option than simply rectifying ACL graft position.

Additional research is needed to standardize outcomes, highlighting validated subjective and objective scores and knee stability tests, and to evaluate ACL reconstruction failure during long-term followup. In addition, combined intra- and extraarticular ACL reconstruction should be 
done using current anatomic isolated intraarticular techniques. Strict and standardized inclusion criteria also are needed to determine the types of ACL injuries that will benefit from combined reconstruction techniques. Revision and challenging primary cases should be taken into account. Although our study presents the best available evidence on the topic, methodologic refinements must be adopted to strengthen the quality of the evidence. Proper randomization and allocation concealment along with detailed descriptions of procedures used to blind participants and collect outcome data are needed to improve future trials.

Patient-reported outcome scores (postoperative IKDC scores, Tegner Lysholm scores, and return-to-activity level) were similar between the two treatment groups, showing that the association of the extraarticular procedure did not influence final clinical results. These findings confirm what individual trials have shown [1-3], and even our larger sample size did not change that. Therefore, combining or not combining the extraarticular surgery should not be the primary concern in ACL surgery, at least regarding the overall population with ACL injuries. Further primary aspects in ACL surgery, such as fixation methods, correct tunnel placement, and postoperative programs [47], possibly have greater influence in final clinical results and should be addressed before considering the combined procedure.

Improved pivot shift stability in the combined procedure was expected given the role of extraarticular repair as a secondary restraint to rotational control [8]. Some ACL injuries may be more complex than previously believed, and a combination of central and peripheral structures appear to be involved in the pathoanatomy of pivot shift injury. Previous studies also have shown that the addition of an extraarticular lateral restraint can decrease rotational instability, as assessed by the pivot shift test [12, 13, 24]. Understanding the improved Lachman test results among patients who underwent combined ACL reconstruction is less straightforward. The improvement may be related to the protective effect of the extraarticular procedure during the ligamentization process. During ligamentization, the graft is subject to various forces that can deform, elongate, or even rupture it. The forces may be partially dissipated by the extraarticular procedure thereby preventing some elongation and optimizing the biomechanical environment for ligamentization [7, 31]. Results of subgroup analyses regarding type of graft also support these findings. Unlike the comparison using only BPTB grafts for intraarticular reconstruction in combined and isolated ACL reconstruction groups, analysis of procedures using only hamstring grafts showed that a substantially greater proportion of patients who underwent combined reconstruction achieved normal or nearly normal Lachman test results and side-to- side differences less than $3 \mathrm{~mm}$ on KT-1000 arthrometer testing. Results of our subgroup analyses of superior stability of BPTB grafts compared with hamstring grafts may be related to the delayed ligamentization of hamstring tendons as opposed to BPTB grafts [7, 11, 31]. As a result, the hamstring graft may be more disposed to deformation and elongation during ligamentization, which may be prevented by the addition of an extraarticular procedure [32]. However, the differences we found in terms of additional stability with the combined procedure were small, and although they were statistically significant, it is possible that they were not clinically important. Previous studies have determined a direct correlation between objective assessment of ligament stability and subjective outcomes of function $[4,19]$. As our results indicate that patient-reported functional outcomes were similar between both treatment groups, we may assume that the slight increase in stability offered by the addition of the extraarticular procedure did not reach a minimum threshold to be clinically perceptible to patients. Future studies will need to determine whether the incremental benefits in joint stability with a combined approach justify the added surgery associated with the combined approach.

Complications and adverse events did not differ between the groups in our study. Our meta-analysis found no difference between the two treatments in terms of the proportion of patients whose reconstructions failed, however graft failure was reported in only two studies $[1,3]$ included in our analysis. Because revision rates are higher for hamstring ACL reconstruction than for BPTB ACL reconstruction [33, 35], analysis of a larger, pooled sample size may reveal a lower failure rate after combined ACL reconstruction when hamstring grafts are used. The Lemaire technique for extraarticular lateral tenodesis has been associated with osteoarthritis affecting the lateral side of the knee, suggesting that the addition of an extraarticular procedure can cause early degenerative changes [30]. Nevertheless, our study showed no difference in the proportion of patients with radiographic evidence of degenerative changes between the two treatment groups, which is consistent with findings in the literature [24, 32]. In contrast to other studies [3, 15], we found no difference between the two groups regarding knee stiffness. The postoperative rehabilitation program may have negatively influenced the results of Anderson et al. [3] and Goertzen and Schulitz [15], which were based on immobilization with a brace and early restricted ROM. Despite the additional lateral knee incision required for the extraarticular procedure and some authors suggesting a higher infection rate with the combined procedure [39], this complication was similar in both treatment groups. Ultimately, reoperation rates for recurrent meniscal injuries were not different in the two intervention groups. Nevertheless, all 
adverse events were underreported in the trials included in this review, therefore future data with longer followup will enhance the power of these analyses.

The strengths of our meta-analysis include a preestablished protocol to identify relevant outcomes after ACL reconstruction, including patient function indicated by IKDC scores, Tegner Lysholm scores, and proportion of patients able to return to previous activity level; knee stability tests; and adverse events such as graft failure rates. In addition, the demographic characteristics of the patients were relatively homogeneous and the included studies showed relatively high internal validity. We found that combined intra- and extraarticular ACL reconstruction showed no difference in knee function compared with intraarticular ACL reconstruction only. Although some advantage was shown regarding knee-stability tests after combined reconstruction, it remains unclear whether it is justified at the cost of an additional procedure. Data indicate that the addition of the extraarticular procedure provided superior stability to ACL procedures with hamstrings grafts. In contrast, ACL procedures with BPTB grafts did not show stability improvement when comparing combined ACL reconstruction with isolated intraarticular reconstruction. Future studies are needed to determine which groups of patients might benefit from combined ACL reconstruction. Research should focus on detecting complications, such as graft failure and knee stiffness, because data regarding adverse events after combined ACL reconstruction are limited.

\section{References}

1. Acquitter Y, Hulet C, Locker B, Delbarre JC, Jambou S, Vielpeau C. [Patellar tendon-bone autograft reconstruction of the anterior cruciate ligament for advanced-stage chronic anterior laxity: is an extra-articular plasty necessary? A prospective randomized study of 100 patients with five-year follow-up] [In French]. Rev Chir Orthop Reparatrice Appar Mot. 2003;89:413-422.

2. Ait Si Selmi T, Fabie F, Massouh T, Adeleine P, Neyret P. Greffe du LCA au tendon rotulien sous arthroscopie avec ou sans plastie antéro-externe: etude prospective randomisée à propos de 120 cas. In: Chambat P, Neyret P, Deschamps G et al., eds. Le Genou $d u$ Sportif. Montpellier, France: Sauramps Medical; 2002:221.

3. Anderson AF, Snyder RB, Lipscomb AB Jr. Anterior cruciate ligament reconstruction: a prospective randomized study of three surgical methods. Am J Sports Med. 2001; 29:272-279.

4. Ayeni OR, Chahal M, Tran MN, Sprague S. Pivot shift as an outcome measure for ACL reconstruction: a systematic review. Knee Surg Sports Traumatol Arthrosc. 2012;20:767-777.

5. Bull AM, Amis AA. The pivot-shift phenomenon: a clinical and biomechanical perspective. Knee. 1998;5:141-158.

6. Chouliaras V, Ristanis S, Moraiti C, Stergiou N, Georgoulis AD. Effectiveness of reconstruction of the anterior cruciate ligament with quadrupled hamstrings and bone-patellar tendon-bone autografts: an in vivo study comparing tibial internal-external rotation. Am J Sports Med. 2007;35:189-196.
7. Claes S, Verdonk P, Forsyth R, Bellemans J. The "ligamentization" process in anterior cruciate ligament reconstruction: what happens to the human graft? A systematic review of the literature. Am J Sports Med. 2011;39:2476-2483.

8. Claes S, Vereecke E, Maes M, Victor J, Verdonk P, Bellemans J. Anatomy of the anterolateral ligament of the knee. J Anat. 2013;223:321-328.

9. Corry IS, Webb JM, Clingeleffer AJ, Pinczewski LA. Arthroscopic reconstruction of the anterior cruciate ligament: a comparison of patellar tendon autograft and four-strand hamstring tendon autograft. Am J Sports Med. 1999;27:444-454.

10. Dandy DJ. Some clinical aspects of reconstruction for chronic anterior cruciate ligament deficiency. Ann R Coll Surg Engl. 1995;77:290-298.

11. da Silveira Franciozi CE, Ingham SJ, Gracitelli GC, Luzo MV, Fu $\mathrm{FH}$, Abdalla RJ. Updates in biological therapies for knee injuries: anterior cruciate ligament. Curr Rev Musculoskelet Med. 2014;7: 228-238.

12. Dodds AL, Gupte CM, Neyret P, Williams AM, Amis AA. Extraarticular techniques in anterior cruciate ligament reconstruction: a literature review. J Bone Joint Surg Br. 2011; 93:1440-1448.

13. Engebretsen L, Lew WD, Lewis JL, Hunter RE. The effect of an iliotibial tenodesis on intra-articular graft forces and knee joint motion. Am J Sports Med. 1990;18:169-176.

14. Giraud B, Besse JL, Cladière F, Ecochard R, Moyen B, Lerat JL. [Intra-articular reconstruction of the anterior cruciate ligament with and without extra-articular supplementation by quadricipital tendon plasty: seven-year follow-up] [In French]. Rev Chir Orthop Reparatrice Appar Mot. 2006;92:788-797.

15. Goertzen M, Schulitz KP. [Isolated intraarticular plasty of the semitendinosus or combined intra- and extra-articular plasty in chronic anterior laxity of the knee] [In French]. Rev Chir Orthop Reparatrice Appar Mot. 1994;80:113-117.

16. Higgins JP, Altman DG, Gotzsche PC, Jüni P, Moher D, Oxman AD, Savovic J, Schulz KF, Weeks L, Sterne JA; Cochrane Bias Methods Group; Cochrane Statistical Methods Group. The Cochrane Collaboration's tool for assessing risk of bias in randomised trials. BMJ. 2011;343:d5928.

17. Hughston JC. Anterior cruciate deficient knee. Am J Sports Med. 1983;11:1-2.

18. Irrgang JJ, Anderson AF, Boland AL, Harner CD, Kurosaka M, Neyret P, Richmond JC, Shelborne KD. Development and validation of the International Knee Documentation Committee subjective knee form. Am J Sports Med. 2001;29:600-613.

19. Kocher MS, Steadman JR, Briggs KK, Sterett WI, Hawkins RJ. Relationships between objective assessment of ligament stability and subjective assessment of symptoms and function after anterior cruciate ligament reconstruction. Am J Sports Med. 2004;32:629-634.

20. Liberati A, Altman DG, Tetzlaff J, Mulrow C, Gotzsche PC, Ionnidis JP, Clarke M, Devereaux PJ, Kleijnen J, Moher D. The PRISMA statement for reporting systematic reviews and metaanalyses of studies that evaluate healthcare interventions: explanation and elaboration. BMJ. 2009;339:b2700.

21. Logan MC, Williams A, Lavelle J, Gedroyc W, Freeman M. Tibiofemoral kinematics following successful anterior cruciate ligament reconstruction using dynamic multiple resonance imaging. Am J Sports Med. 2004;32:984-992.

22. Losee RE, Johnson TR, Southwick WO. Anterior subluxation of the lateral tibial plateau: a diagnostic test and operative repair. $J$ Bone Joint Surg Am. 1978;60:1015-1030.

23. Lysholm J, Gillquist J. Evaluation of knee ligament surgery results with special emphasis on use of a scoring scale. Am J Sports Med. 1982;10:150-154.

24. Marcacci M, Zaffagnini S, Giordano G, Iacono F, Presti ML. Anterior cruciate ligament reconstruction associated with extra- 
articular tenodesis: a prospective clinical and radiographic evaluation with 10- to 13-year follow-up. Am J Sports Med. 2009;37:707-714.

25. McGuire DA, Wolchok JC. Extra-articular lateral reconstruction technique. Arthroscopy. 2000;16:553-557.

26. Meredick RB, Vance KF, Appleby D, Lubowitz JH. Outcome of single-bundle versus double-bundle reconstruction of the anterior cruciate ligament: a meta-analysis. $A m$ J Sports Med. 2008;36:1414-1421.

27. Misonoo G, Kanamori A, Ida H, Miyakawa S, Ochiai N. Evaluation of tibial rotational stability of single-bundle vs. anatomical double-bundle anterior cruciate ligament reconstruction during a high-demand activity: a quasi-randomized trial. Knee. 2012;19:87-93.

28. Monaco E, Ferretti A, Labianca L, Maestri B, Speranza A, Kelly MJ, D'Arrigo C. Navigated knee kinematics after cutting of the ACL and its secondary restraint. Knee Surg Sports Traumatol Arthrosc. 2012;20:870-877.

29. Monaco E, Labianca L, Conteduca F, De Carli A, Ferretti A. Double bundle or single bundle plus extraarticular tenodesis in ACL reconstruction? A CAOS study. Knee Surg Sports Traumatol Arthrosc. 2007;15:1168-1174.

30. O'Brien SJ, Warren RF, Wickiewicz TL, Rawlins BA, Allen AA, Panariello R, Kelly AM. The iliotibial band lateral sling procedure and its effect on the results of anterior cruciate ligament reconstruction. Am J Sports Med. 1991;19:21-24; discussion 2425.

31. Pauzenberger L, Syré S, Schurz M. "Ligamentization" in hamstring tendon grafts after anterior cruciate ligament reconstruction: a systematic review of the literature and a glimpse into the future. Arthroscopy. 2013;29:1712-1721.

32. Pernin J, Verdonk P, Si Selmi TA, Massin P, Neyret P. Long-term follow-up of 24.5 years after intra-articular anterior cruciate ligament reconstruction with lateral extra-articular augmentation. Am J Sports Med. 2010;38:1094-1102.

33. Persson A, Fjeldsgaard K, Gjertsen JE, Kjellsen AB, Engebretsen L, Hole RM, Fevang JM. Increased risk of revision with hamstring tendon grafts compared with patellar tendon grafts after anterior cruciate ligament reconstruction: a study of 12,643 patients from the Norwegian Cruciate Ligament Registry, 2004-2012. Am J Sports Med. 2014;42:285-291.

34. Petersen W, Zantop T. Anatomy of the anterior cruciate ligament with regard to its two bundles. Clin Orthop Relat Res. 2007;454:35-47.

35. Reinhardt KR, Hetsroni I, Marx RG. Graft selection for anterior cruciate ligament reconstruction: a level I systematic review comparing failure rates and functional outcomes. Orthop Clin North Am. 2010; 41:249-262.

36. Riboh JC, Hasselblad V, Godin JA, Mather RC 3rd. Transtibial versus independent drilling techniques for anterior cruciate ligament reconstruction: a systematic review, meta- analysis, and meta-regression. Am J Sports Med. 2013;41: 2693-2702.

37. Ristanis S, Stergiou N, Patras K, Vasiliadis HS, Giakas G, Gergoulis $\mathrm{AD}$. Excessive tibial rotation during high-demand activities is not restored by anterior cruciate ligament reconstruction. Arthroscopy. 2005;21:1323-1329.

38. Roth JH, Kennedy JC, Lockstadt H, McCallum CL, Cunning LA. Intra-articular reconstruction of the anterior cruciate ligament with and without extra-articular supplementation by transfer of the biceps femoris tendon. J Bone Joint Surg Am. 1987; 69:275-280.

39. Sonnery-Cottet B, Archbold P, Zayni R, Bortolletto J, Thaunat M, Prost T, Padua VB, Chambat P. Prevalence of septic arthritis after anterior cruciate ligament reconstruction among professional athletes. Am J Sports Med. 2011;39:2371-2376.

40. Tegner Y, Lysholm J. Rating systems in the evaluation of knee ligament injuries. Clin Orthop Relat Res. 1985;198:43-49.

41. The Nordic Cochrane Centre, The Cochrane Collaboration. Review Manager (RevMan) [Computer program] Version 5.1. Copenhagen, Denmark: The Nordic Cochrane Centre, The Cochrane Collaboration; 2011.

42. Trichine F, Alsaati M, Chouteau J, Moyen B, Bouzitouna M, Maza R. Patellar tendon autograft reconstruction of the anterior cruciate ligament with and without lateral plasty in advanced-stage chronic laxity: a clinical, prospective, randomized, single-blind study using passive dynamic X-rays. Knee. 2014;21:58-65.

43. University of York Centre for Reviews and Dissemination; National Institute for Health Research. PROSPERO International prospective register of systematic reviews. Available at: http:// www.crd.york.ac.uk/PROSPERO/display_record.asp?ID=CRD 42013004587. Accessed April 15, 2014.

44. Yagi M, Wong EK, Kanamori A, Debski RE, Fu FH, Woo SL. Biomechanical analysis of an anatomic anterior cruciate ligament reconstruction. Am J Sports Med. 2002;30:660-666.

45. Yasuda K, Kondo E, Ichiyama H, Kitamura N, Tanabe Y, Tohyama $\mathrm{H}$, Minami A. Anatomic reconstruction of the anteromedial and posterolateral bundles of the anterior cruciate ligament using hamstring tendon grafts. Arthroscopy. 2004;20:1015-1025.

46. Zaffagnini S, Bruni D, Russo A, Takazawa Y, Lo Presti M, Giordano G, Marcacci M. ST/G ACL reconstruction: double strand plus extra-articular sling vs double bundle, randomized study at 3-year follow-up. Scand J Med Sci Sports. 2008;18:573-581.

47. Zaffagnini S, Marcacci M, Lo Presti M, Giordano G, Iacono F, Neri MP. Prospective and randomized evaluation of ACL reconstruction with three techniques: a clinical and radiographic evaluation at 5 years follow-up. Knee Surg Sports Traumatol Arthrosc. 2006;14:1060-1069.

48. Zaffagnini S, Marcheggiani Muccioli GM, Lopomo N, Signorelli C, Bonanzinga T, Musiani C, Vassilis P, Nitri M, Marcacci M. Can the pivot-shift be eliminated by anatomic double-bundle anterior cruciate ligament reconstruction? Knee Surg Sports Traumatol Arthrosc. 2012;20:743-751. 